Vol. 2, No. 5, May, 2016

\title{
Experimental and Numerical Investigation on Shear Retrofitting of RC Beams by Prefabricated UHPFRC Sheets
}

\author{
Kian Aghani ${ }^{a^{*}}$, Hassan Afshin ${ }^{\mathrm{b}}$ \\ ${ }^{a}$ MSc in Civil Engineering, Sahand University of Technology, Tabriz, Iran \\ ${ }^{b}$ Associate Professor, Civil Engineering Department, Sahand University of technology, Tabriz, Iran \\ Received 17 April 2016; Accepted 23 May 2016
}

\begin{abstract}
Different methods are used for retrofitting RC members. One of the new methods in this field is using externally bonded fiber-reinforced Concrete (FRC) sheets in order to increase RC member's shear and flexural strength. In this study, applicability of ultra-high performance fiber-reinforced concrete sheets in shear and flexural retrofitting of RC beams was investigated. In total, eight RC beams (dimensions $10 \times 20 \times 150 \mathrm{~cm}$ ) with two different bending capacity and lack of shear strength were used and were tested in 3-points bending test. Of these, four were control beams and four were retrofitted with laterally bonded UHPFRC sheets. Dimensions of the sheets used for retrofitting were $(3 \times 15 \times 126 \mathrm{~cm})$. Also FEM analysis was used to model the effect of The method. the results show that this method can be well used for retrofitting RC beams. In this method the way of connecting sheets to beam's surfaces has a fundamental role in behavior of retrofitted beams.
\end{abstract}

Keywords: Reinforced Concrete Structures; UHPFRC; Retrofitting; Laterally Bonded Sheets.

\section{Introduction}

Different methods are provided for retrofitting RC members such as using FRP, steel and concrete jacketing, shotcrete. Each approach has advantages and disadvantages which must be inspected by the project engineer. As technology advanced, a new type of fiber-reinforced concrete called ultra-high-performance fiber-reinforced concrete (UHPFRC) was produced, which continues to gain attention of engineers and professionals in the industry. UHPFRC has good compressive, tensile bending strength, resistance to environmental factors like freeze and thaw cycles, high corrosion resistance and ductility. The fiber content ranges from 1 vol.\% to 4 vol. $\%$. The maximum compressive and flexural strength of UHPFRC are up to about $200 \mathrm{MPa}$ and $40 \mathrm{MPa}$ [1].

Recently applicability of UHPFRC as a repairing/retrofitting agent is investigated. Studies have showed that using UHPFRC as the reinforcing layer can be used to improve specimen weakness. Tayeh et al. (2012) used UHPFRC to form a new overlay to develop a bonding layer between the deteriorated concrete structures. Their results showed that the overlay technique achieved high bond strength [2]. Iskhakov et al. (2013) proposed a repair method to increase bending moment and ultimate deformation of member by casting steel-fibered high-strength concrete in member's compression zones. Their results showed high ductile behavior until failure but debonding between concrete layers made this method unreliable [3]. Martinola et al. (2010) pointed out that installing UHPFRC jackets can increase shear capacity of RC members [4]. Wang et al. (2014) used ultra-high strength fiber-reinforced concrete (UFC) for shear retrofitting of RC beams. Their results showed high increase in shear strength of the specimens but the debonding problem still occurred [1]. Rosignoli et al. (2012) used UHPFRC for seismic retrofitting. They used UHPFRC jacketing to retrofit a RC column and used a cyclic loading to evaluate the RC column capacity. Their result showed significant increase in bearing capacity and ductility of RC member [5]. Bruhwiler et al. (2012) showed that using

Corresponding author: kian.aghani@gmail.com 
UHPFRC for RC section rehabilitation can reach positive results [6]. In this paper, authors propose new shear retrofitting method for reinforced concrete beams in which the prefabricated UHPFRC sheets are bonded to RC beam's side surfaces, and studied the strengthening effect of the method.

\section{Methodology}

\subsection{Specimens Properties}

In this paper, the proposed method aims to prevent shear cracks around the end of the RC beams from developing by bonding them to prefabricated UHPFRC sheets. To achieve this approach, RC beams were produced and were divided into two groups, first group were designed to have shear failure and second group were designed to have flexural failure. Both groups had lack of shear reinforcement. In total, two group of four RC beams with identical dimensions $(10 \times 20 \times 150 \mathrm{~cm})$ were produced and were loaded with a 3-points bending configuration. In every group, two RC beams were control beams and two RC beams were retrofitted with prefabricated UHPFRC sheets. All beams were cast is steel mould. The list of specimens is shown in table 1.

Table 1. Specimens properties

\begin{tabular}{ccccc}
\hline Specimen & Type & $\begin{array}{c}\text { Tensile } \\
\text { reinforcement }\end{array}$ & $\begin{array}{c}\text { Compression } \\
\text { reinforcement }\end{array}$ & $\begin{array}{c}\text { Shear } \\
\text { reinforcement }\end{array}$ \\
\hline B & Control beam & $2 \Phi 10$ & $2 \Phi 6$ & $\Phi 6 @ 20 \mathrm{~cm}$ \\
S & Control beam & $2 \Phi 12$ & $2 \Phi 6$ & $\Phi 6 @ 20 \mathrm{~cm}$ \\
B-re & Retrofitted & $2 \Phi 10$ & $2 \Phi 6$ & $\Phi 6 @ 20 \mathrm{~cm}$ \\
S-re & Retrofitted & $2 \Phi 12$ & $2 \Phi 6$ & $\Phi 6 @ 20 \mathrm{~cm}$ \\
\hline
\end{tabular}

All beams had same loading span. The yield strength of tensile reinforcement was $400 \mathrm{MPa}$. The compression and shear reinforcement were for maintenance only.

\subsection{Concrete Properties}

Mix design of the NC and the UHPFRC are shown in table 2. The average compressive strength of standard cylindrical concrete specimens for NC and UHPFRC were $34 \mathrm{MPa}$ and $140 \mathrm{MPa}$, respectively. The length and diameter of the steel fibers used were $30 \mathrm{~mm}$ and $0.75 \mathrm{~mm}$ (aspect ratio 40), the tensile and flexural strength of the steel fibers were $1100 \mathrm{MPa}$ and $800 \mathrm{MPa}$, respectively (ASTM A 820).

Table 2. Mix design of NC and UHPFRC

\begin{tabular}{ccc}
\hline Materials & UHPFRC $\left(\mathbf{K g} / \mathbf{m}^{\mathbf{3}}\right)$ & $\mathbf{N C ~}\left(\mathbf{K g} / \mathbf{m}^{3}\right)$ \\
\hline Cement & 928 & 372 \\
Water & 207 & 211 \\
Sand & - & 965 \\
Silica sand & 877 & - \\
Gravel & - & 855 \\
Ground quartz & 77 & - \\
Super plasticizer & 29 & - \\
Silica fume & 222 & - \\
Steel fiber & 157 & - \\
\hline
\end{tabular}

\subsection{UHPFRC Sheets Properties and Bonding}

For all beam types, thickness of the prefabricated UHPFRC sheets was $30 \mathrm{~mm}$. This was set to ensure random distribution of the steel fibers. Figure 1 shows prefabricated UHPFRC sheets after curing. For bonding sheets to the beam's surfaces, a type of adhesive epoxy was used. Mechanical properties of epoxy are as shown in table 3 . In this study, for better bonding between UHPFRC sheets and the beam surface, a lumpy surface was placed in UHPFRC mould, when casting UHPFRC. The beam surfaces were roughened by disk grinder, then adhesive epoxy was 
distributed on both beam surfaces and UHPFRC sheets, afterwards sheets were fixed onto beam surfaces as shown in figure 2. bolting or riveting were not used for bonding.

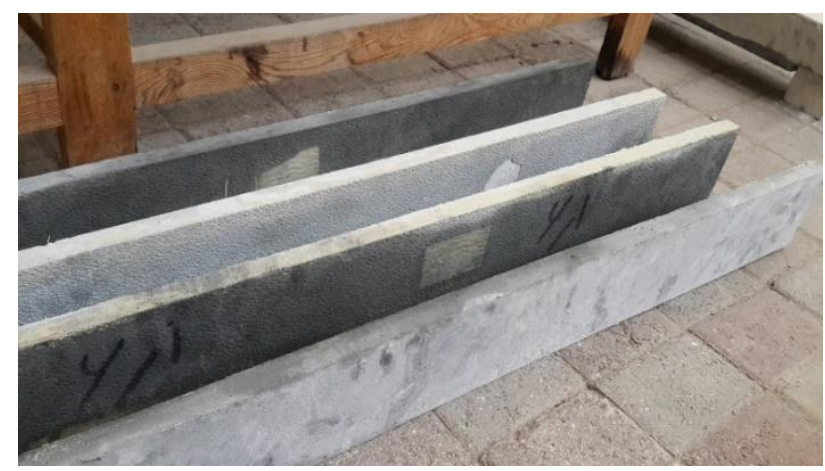

Figure 1. Prefabricated UHPFRC sheets

Table 3. Mechanical properties of adhesive epoxy [7]

\begin{tabular}{ccc}
\hline $\begin{array}{c}\text { Tensile strength } \\
\mathrm{MPa}\end{array}$ & $\begin{array}{c}\text { Flexural modulus } \\
\text { GPa }\end{array}$ & $\begin{array}{c}\text { Tensile modulus } \\
\mathrm{GPa}\end{array}$ \\
\hline 30 & 3.8 & 4.5 \\
\hline
\end{tabular}

\subsection{Three-Points Bending Test}

In this study, to determine the ultimate bearing capacity of control and retrofitted beams, a 3-points bending test with clear span of $130 \mathrm{~cm}$ was used. A 20-ton hydraulic jack was used at the top surface of the beams for load application. A LVDT with opening capacity of $25 \mathrm{~mm}$ was used to measure mid-span deflection. Schematic illustration of 3-points bending test is shown in figure 3 .
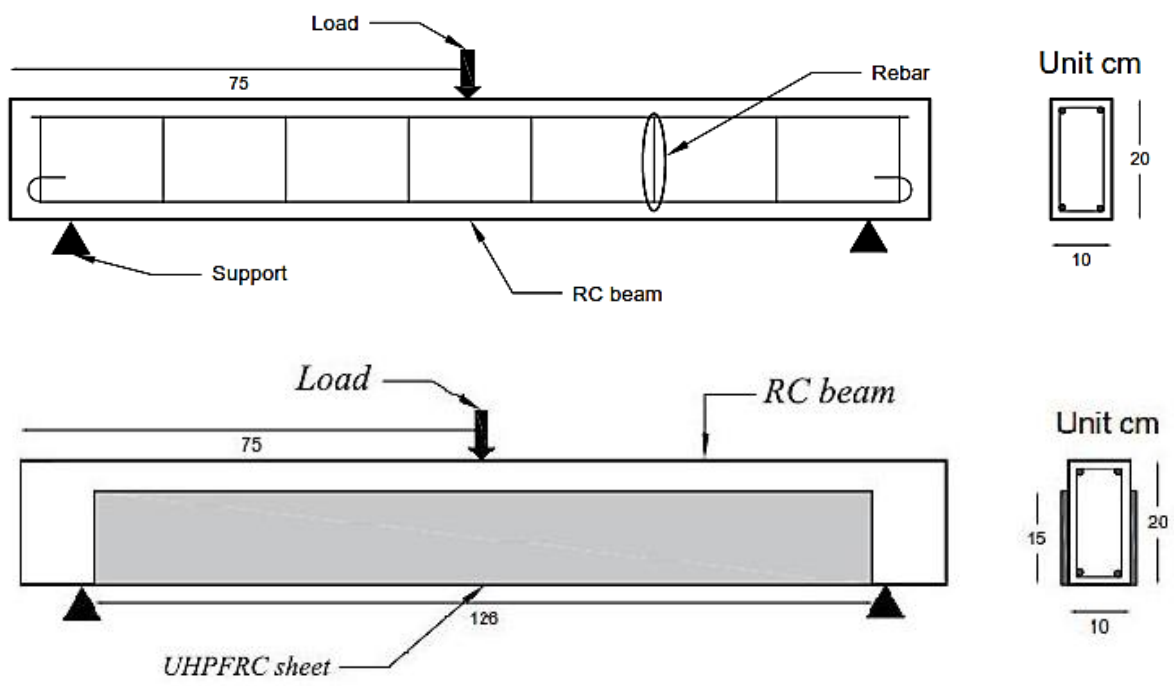

Figure 2. Location of prefabricated UHPFRC sheets

\section{Experimental Results}

\subsection{S and S-re Series}

The load testing results for $\mathrm{S}$ and $\mathrm{S}$-re series are given in table 4. The $\mathrm{S}$ series were broken in shear failure mode. In S-re series prefabricated UHPFRC sheets were bonded to the beams in their shear span. As the results shows, prefabricated UHPFRC sheets were able to alter the failure mechanism to flexural failure and increase the bearing capacity by approximately $23 \%$. No deboning between UHPFRC sheets and beam surfaces was observed. Maximum crack opening was $2 \mathrm{~cm}$. 


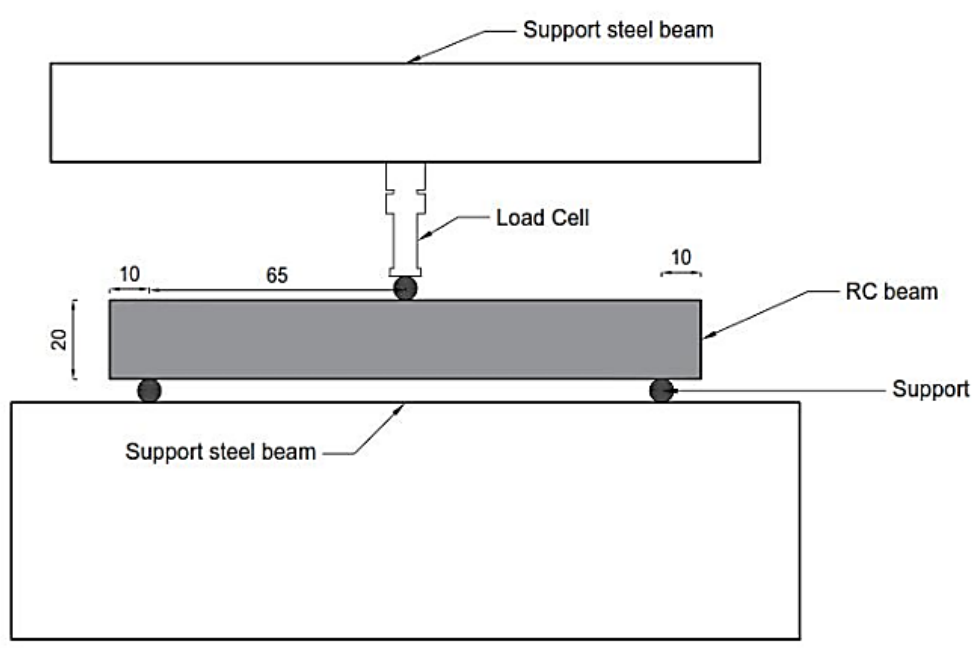

Figure 3. Schematic illustration of 3-point loading test

Table 4. Load testing results for $S$ and $S$-re series

\begin{tabular}{ccc}
\hline Specimens & $\mathbf{P}_{\mathbf{u}}(\mathbf{K N})$ & Failure mode \\
\hline S1 & 58.1 & Shear \\
S2 & 59.7 & Shear \\
S3-re & 73 & Flexural \\
S4-re & 72.3 & Flexural \\
\hline
\end{tabular}

Figure 4 shows load-deflection relationship for S and S-re series. As the results show, energy absorption capacity of the retrofitted beams increased by approximately $278 \%$, as a result of UHPFRC strengthening. The crack pattern for S and S-re series are shown in figure 5, in which the cracks happened in bottom face of the retrofitted beam. A sample of beam's crack opening is shown in figure 6 .

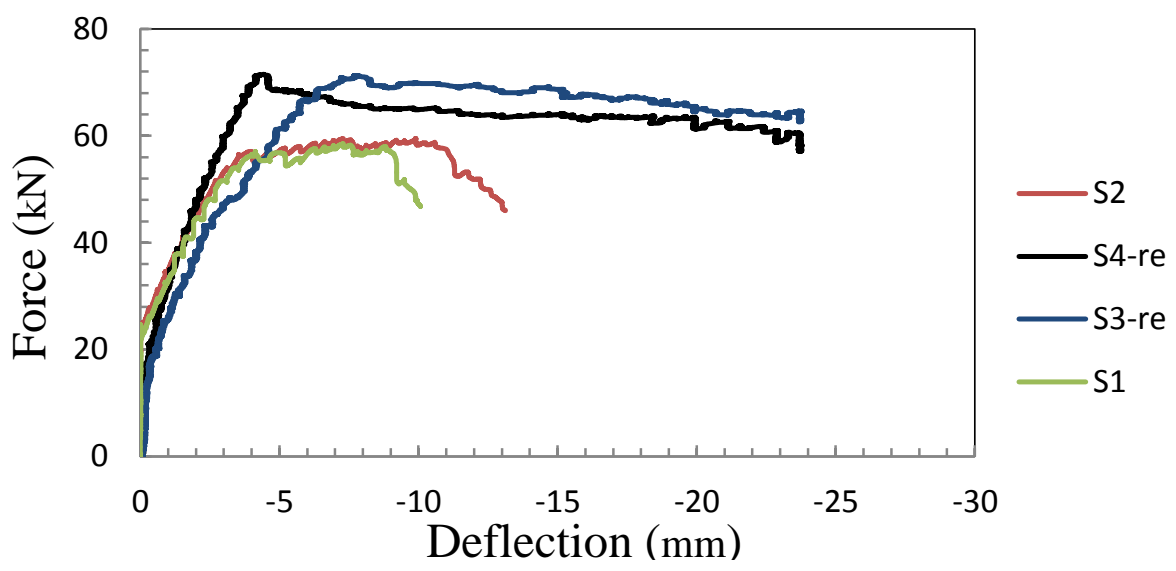

Figure 4. Load-deflection relationship for $\mathrm{S}$ and S-re series 

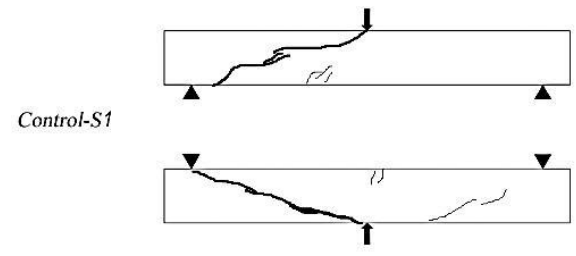

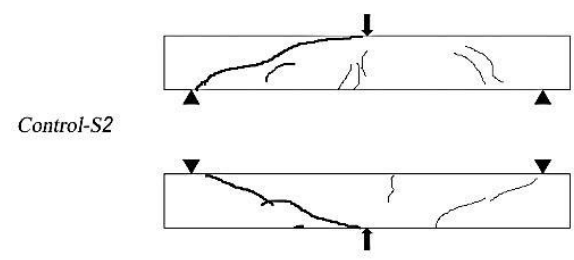

(a)
Retrofitted-S3
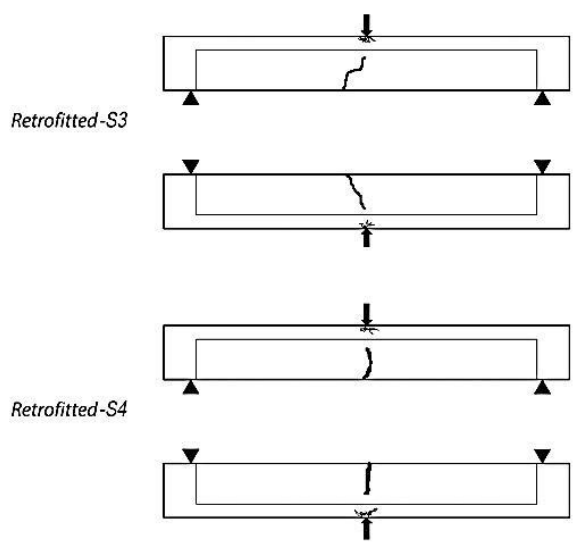

(b)

Figure 5. Crack pattern: (a) S series, (b) S-re series
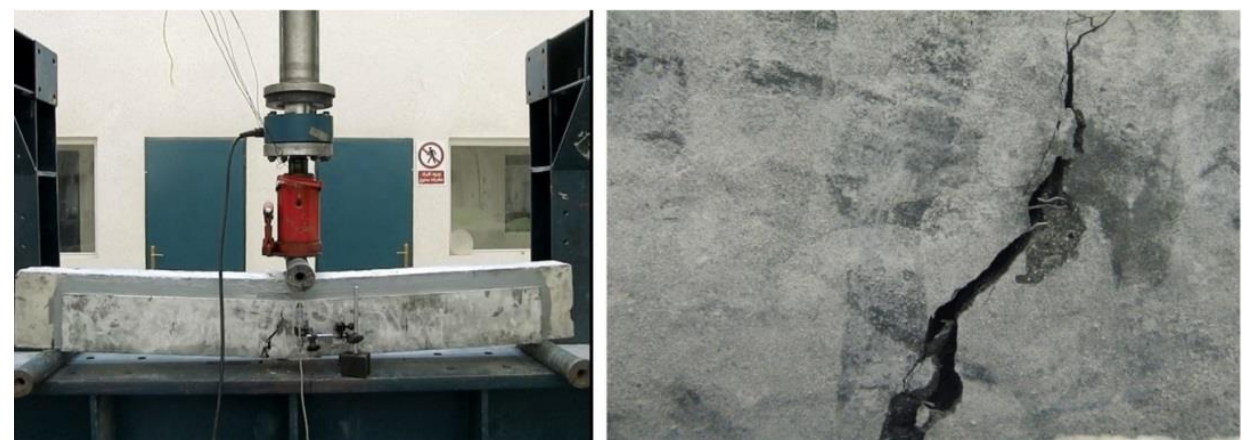

Figure 6. Failure mode of S-re series

\section{2. $B$ and B-re Series}

The load testing results for B and B-re series are given in table 5. The B series were broken in shear-flexural mode. In B-re series prefabricated UHPFRC sheets were bonded to the beams in their shear span. As the results show, prefabricated UHPFRC sheets increase the bearing capacity by approximately $27 \%$ and caused a flexural mode failure. No debonding between UHPFRC sheets and beam surfaces was observed. Maximum crack opening was $3 \mathrm{~cm}$.

Table 5. Load testing results for B and B-re series

\begin{tabular}{ccc}
\hline Specimens & $\mathbf{P}_{\mathbf{u}}(\mathbf{K N})$ & Failure mode \\
\hline B1 & 36 & Shear-flexural \\
B4 & 38.2 & Shear-flexural \\
B3-re & 47.5 & Flexural \\
B2-re & 46.8 & Flexural \\
\hline
\end{tabular}


Figure 7 shows the load-deflection relationship for B and B-re series. As the results show, stiffness of the retrofitted beams increased significantly, as a result of UHPFRC strengthening. The crack pattern for B and B-re series are shown in figure 8. A sample of beam's crack opening is shown in figure 9.

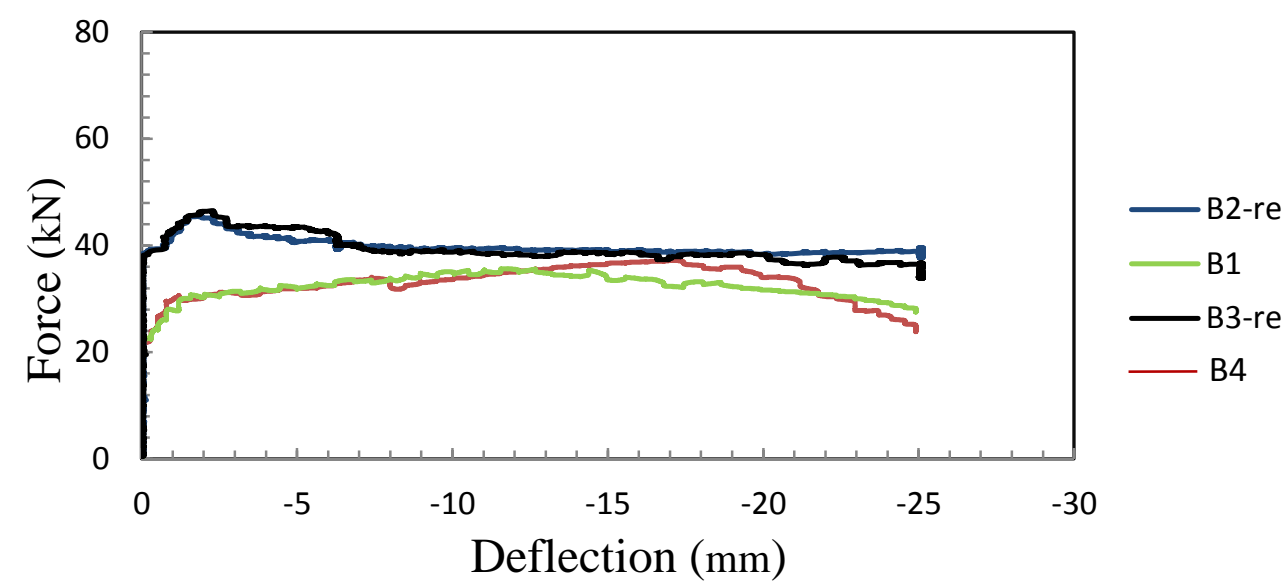

Figure 7. Load-deflection relationship for B and B-re series

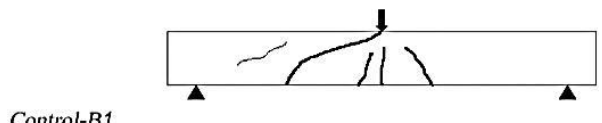

Control-B1
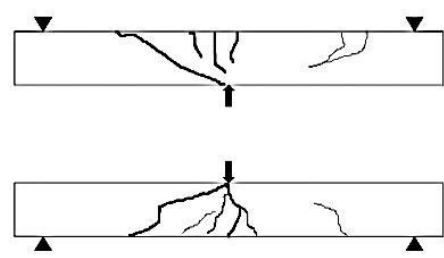

Control-84

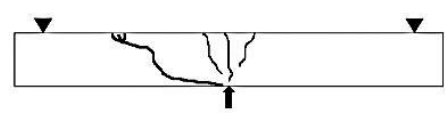

(a)
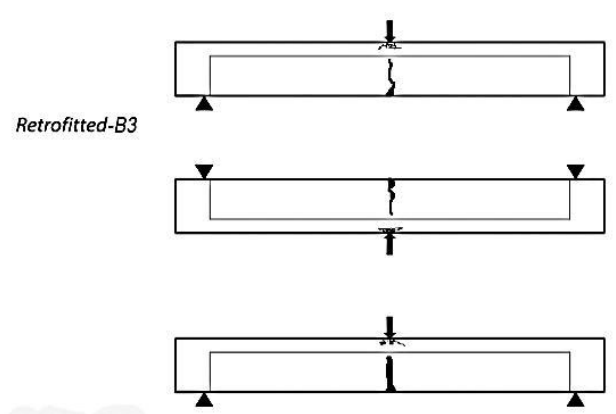

Retrofitted-B2

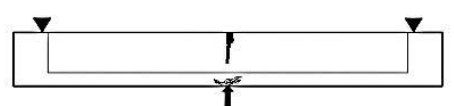

(b)

Figure 8. Crack pattern: (a) B series, (b) B-re series
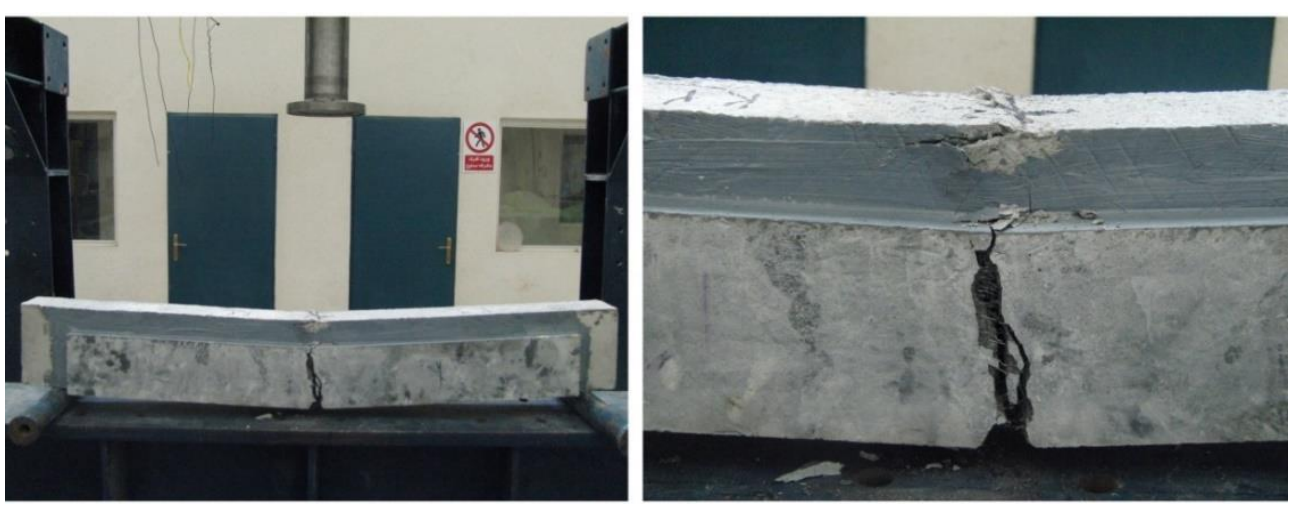

Figure 9. Failure mode of B-re series 


\section{Numerical Analysis}

Finite element failure analysis was performed to model the nonlinear behavior of the beams and to verify the laboratory results. The FEM package abaqus/standard (ABAQUS version 6.12) was used for analysis. Displacement control method was used to determine the bearing capacity and post cracking behavior of the beams.

\subsection{Material Properties and Constitutive Models}

\subsubsection{Concrete}

Concrete damage plasticity theory was used to model the concrete behavior. This model assumes that the main two failure modes are tensile cracking and compressive crushing [8]. The type of element used for concrete was isotropic 8-node solid element which has the ability to be used for nonlinear modelling.

To define the stress-strain relation of concrete in compression, user needs to enter the stresses, inelastic strains corresponds to stress values $\left(\tilde{\varepsilon}_{c}^{i n}\right)$, and damage properties $\left(\mathrm{d}_{\mathrm{c}}\right)$ in tabular format. ABAQUS converts total strain values to the inelastic strains using equation (1):

$\tilde{\varepsilon}_{c}^{i n}=\varepsilon_{c}-\varepsilon_{0}^{c I}$

ABAQUS calculates the plastic strain corresponding to concrete stress using equation (2):

$\tilde{\varepsilon}_{c}^{p I}=\tilde{\varepsilon}_{c}^{i n}-\frac{d_{c}}{\left\langle 1-d_{c}\right\rangle} \frac{\sigma_{c}}{E_{c}}$

Typical compressive stress-strain relationship with damage properties and terms are illustrated in figure 10.

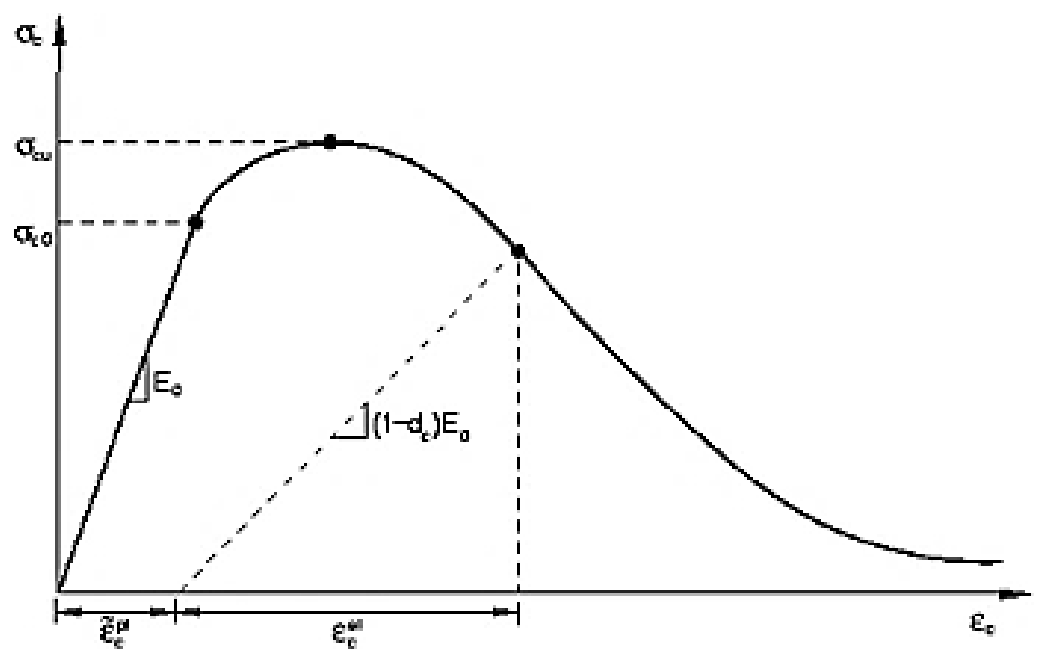

Figure 10. Terms of compressive stress-strain relationship for concrete [9]

In order to define the compressive behavior of concrete in ABAQUS, a Hsu (1994) model was used [10]. This model calculates the concrete stresses using equation (3):

$\sigma_{c}=\left(\frac{\beta\left(\varepsilon_{c} / \varepsilon_{0}\right)}{\beta-1+\left(\varepsilon_{c}-\varepsilon_{0}\right)^{\beta}}\right) \sigma_{c u}$

In which, $\sigma_{c u}$ and $\varepsilon_{0}$ are concrete peak compression strength and the corresponding strain, respectively. The $\beta$ parameter depends on the stress-strain diagram. Table 6 shows the main mechanical properties assumed for normal concrete modelling. 
Table 6. Mechanical properties assumed for NC

\begin{tabular}{cccc}
\hline Density $\left(\mathrm{Kg} / \mathrm{m}^{3}\right)$ & Compressive strength (MPa) & Poisson's ratio & Elastic modulus (MPa) \\
\hline 2405 & 34 & 0.2 & 26870 \\
\hline
\end{tabular}

Concrete damage plasticity theory also used for modelling UHPFRC. In order to define the compressive behavior of UHPFRC in ABAQUS, a model proposed by Graybeal was used [11]. This model calculates the concrete stresses using equations (4), (5) and (6):

$f_{c}=\varepsilon_{c} E(1-\alpha)$

$\mathrm{E}=3840 \sqrt{\mathrm{f}_{\mathrm{c}}^{\prime}} \quad M P a$

$\alpha=a e^{\frac{\varepsilon_{c} E}{b f^{\prime} c}}-a$

In which, $\mathrm{a}$ and $\mathrm{b}$ are calculated 0.011 and 0.24 , respectively. Table 7 shows the main mechanical properties assumed for UHPFRC modeling.

Table 7. Mechanical properties assumed for UHPFRC

\begin{tabular}{cccc}
\hline Density $\left(\mathrm{Kg} / \mathrm{m}^{3}\right)$ & Compressive strength (MPa) & Poisson's ratio & Elastic modulus (MPa) \\
\hline 2500 & 140 & 0.21 & 45435 \\
\hline
\end{tabular}

To define the stress-strain relation of concrete in tension, user needs to enter the peak tensile strength, inelastic strains, and damage properties $\left(\mathrm{d}_{\mathrm{t}}\right)$ in tabular format. ABAQUS calculates the plastic strain corresponding to concrete stress using equation (7):

$\tilde{\varepsilon}_{c}^{p I}=\tilde{\varepsilon}_{c}^{i n}-\frac{d_{t}}{\left\langle 1-d_{t}\right\rangle} \frac{\sigma_{t}}{E_{c}}$

Typical tensile stress-strain relationship with damage properties and terms are illustrated in figure 11. ABAQUS default tensile behavior for concrete was used to model the normal concrete behavior. Peak tensile strength of normal concrete and maximum inelastic strain are assumed 3.4 MPa and 0.000126, respectively.

In order to define UHPFRC tensile behavior, Wille's proposed model was used [12]. This model divides the UHPFRC tensile behavior to three phases as shown in figure 12. Peak tensile strength of UHPFRC and maximum crack opening are assumed $9.5 \mathrm{MPa}$ and $1 \mathrm{~cm}$, respectively. 


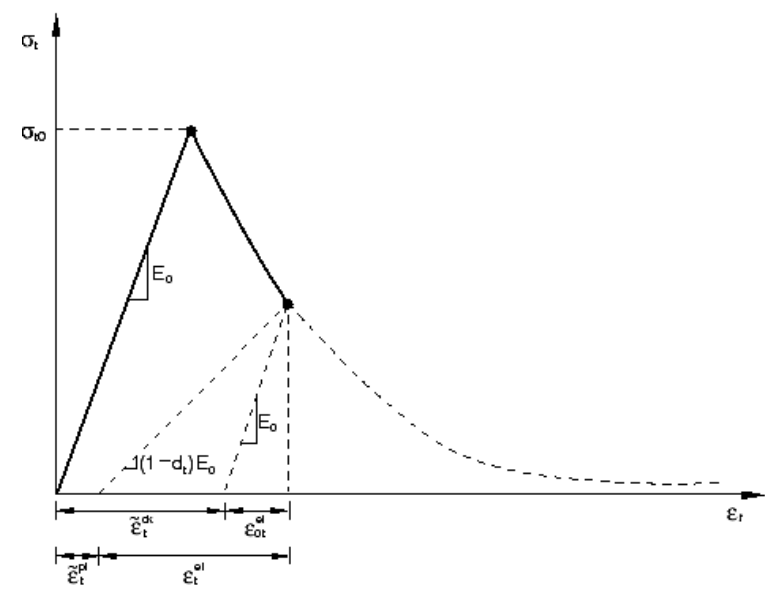

Figure 11. Terms of tensile stress-strain relationship for concrete [9]

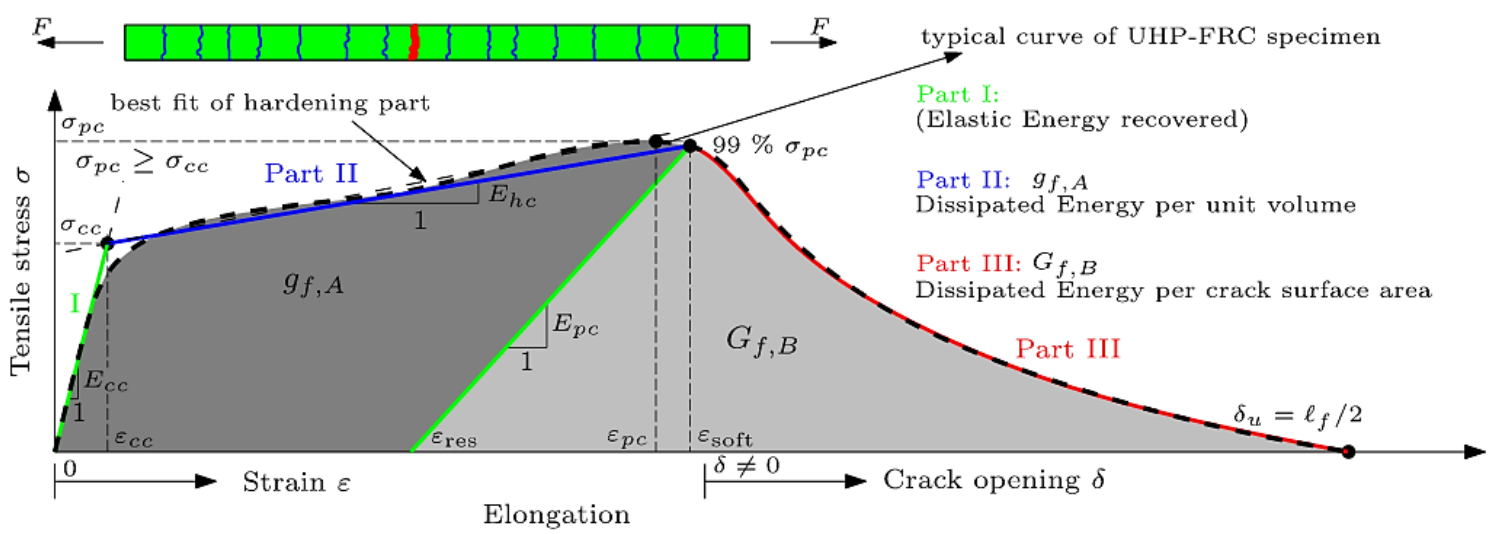

Figure 12. Terms of tensile stress-strain relationship for UHPFRC [12]

\subsubsection{Steel Reinforcement}

To model steel reinforcement, a 3-dimension truss element with elastic-perfectly plastic behavior, identical in tension and compression, was used. Yield strength and Poisson's ratio of steel reinforcement was assumed $400 \mathrm{MPa}$ and 0.3 , respectively.

\subsubsection{Interaction}

ABAQUS default properties were assumed to model the interactions. The bond between steel reinforcement and NC was assumed as perfect bonding. Since there were no debonding between prefabricated UHPFRC sheets and surfaces of the beams, the bond between UHPFRC sheets and beam's surfaces was assumed as perfect bonding.

\section{Numerical Results}

\subsection{S and S-re Series}

Load-deflection curve for beams type S and S-re obtained from experimental and FEM analysis are shown in figure 13. There is good agreement between FEM and experimental results. The jumps in load-deflection curve for $S$ type beam caused by concrete damage plasticity theory which tries to converge after a massive diagonal crack occurred. The FEM analysis of retrofitted beam predicts the beam to be stiffer and stronger which is because of the perfect bonding assumption and lack of information in UHPFRC modelling. Identical to experimental results, FEM analysis for retrofitted beam shows the retrofitting method to be effective in energy absorption. The failure mode of beams type $\mathrm{S}$ and $\mathrm{S}$-re are shown in figure 14. 

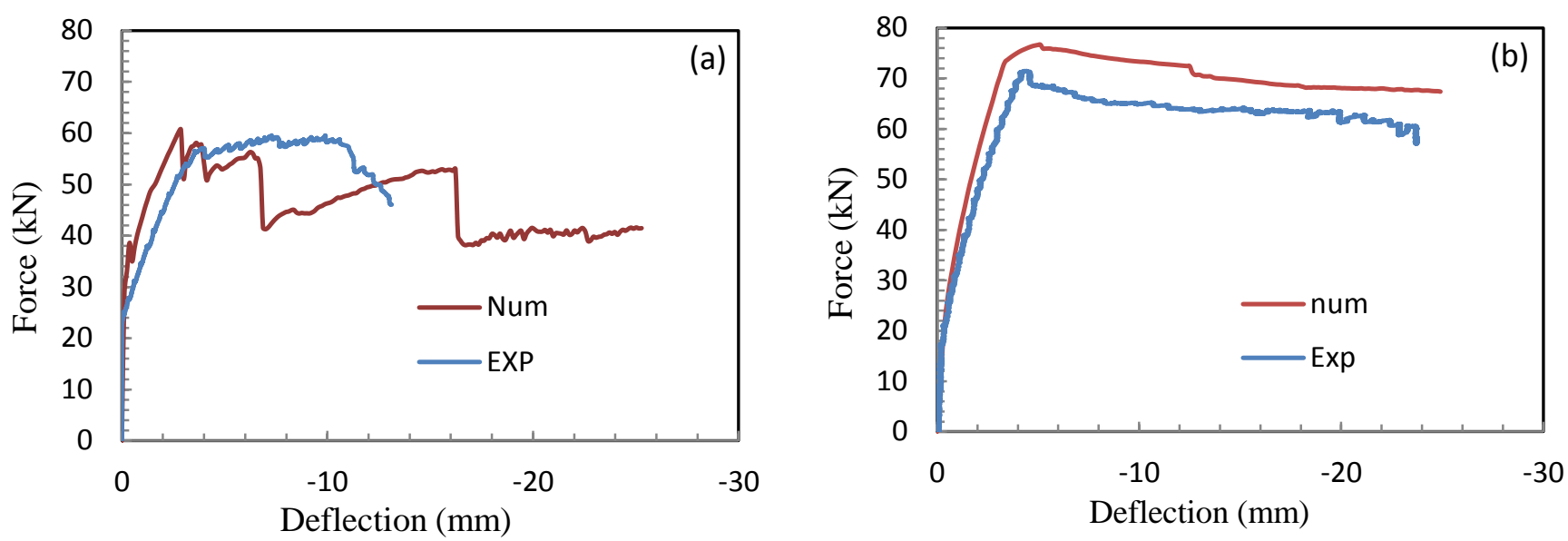

Figure 13. FEM load-deflection relationship: (a) S type; (b) S-re type

a)

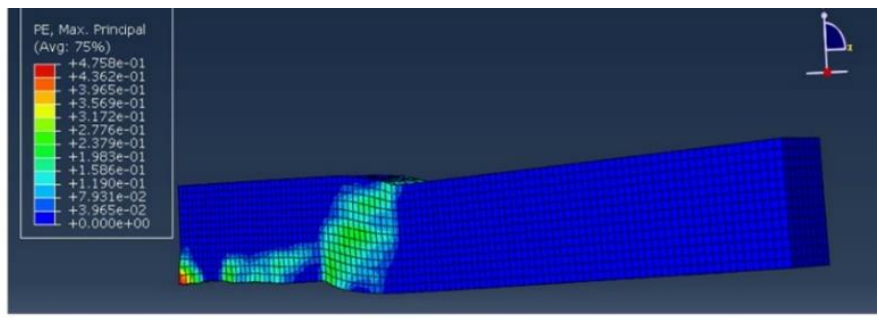

b)

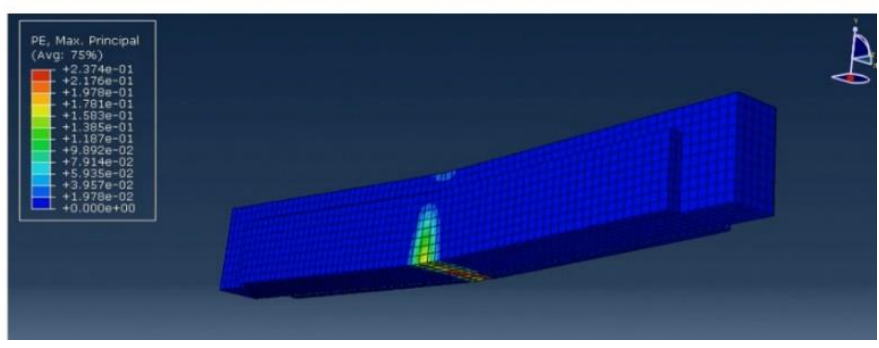

Figure 14. Failure mode of beams: (a) S type; (b) S-re type

\subsection{B and B-re Series}

Load-deflection curve for beams type B and B-re obtained from experimental and FEM analysis are shown in figure 15. There is good agreement between FEM and experimental results. Jump in load-deflection curve for B type beam caused by concrete damage plasticity theory which tries to converge after shear break down. The beam first failed in flexural mode and then large diagonal cracks started to develop, since there was lack of shear reinforcement in B-type beams too. The FEM analysis of retrofitted beam predicts the beam to be stronger which is because of the perfect bonding assumption and lack of information in UHPFRC modelling. The failure mode of beams type B and Bre are shown in figure 16. 

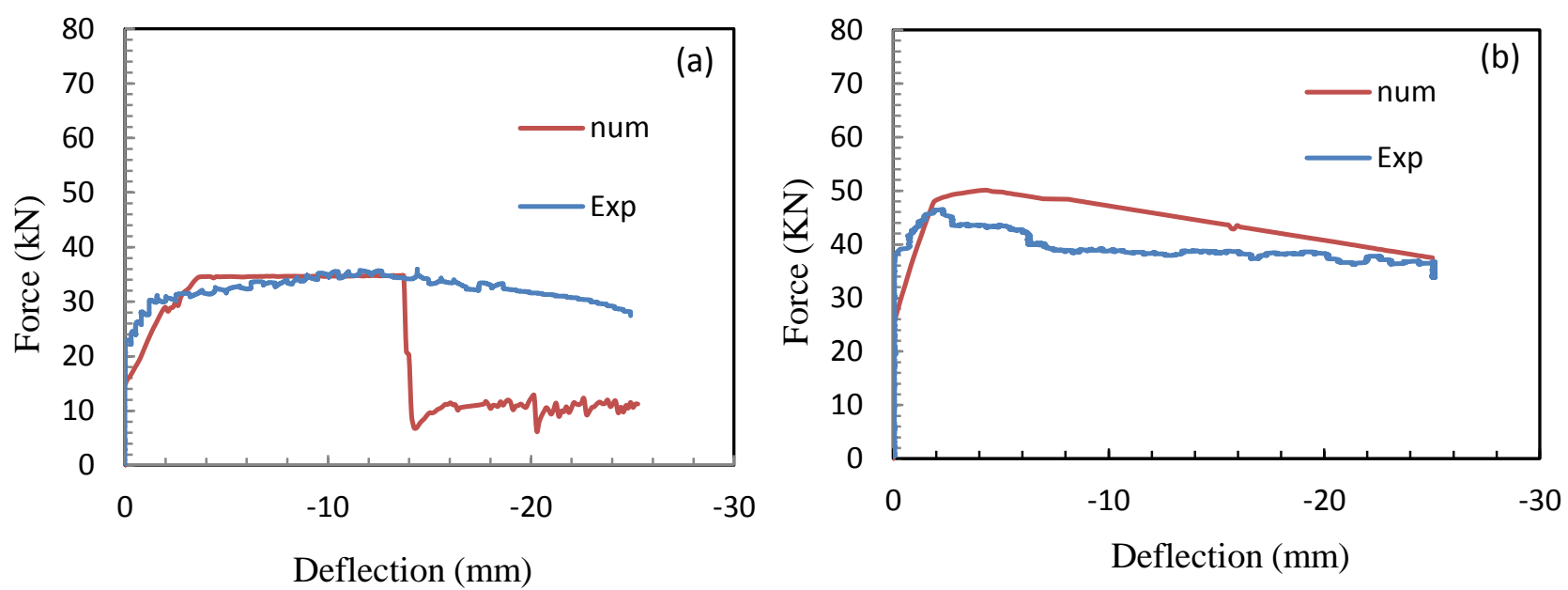

Figure 15. FEM load-deflection relationship: (a) B type; (b) B-re type

a)

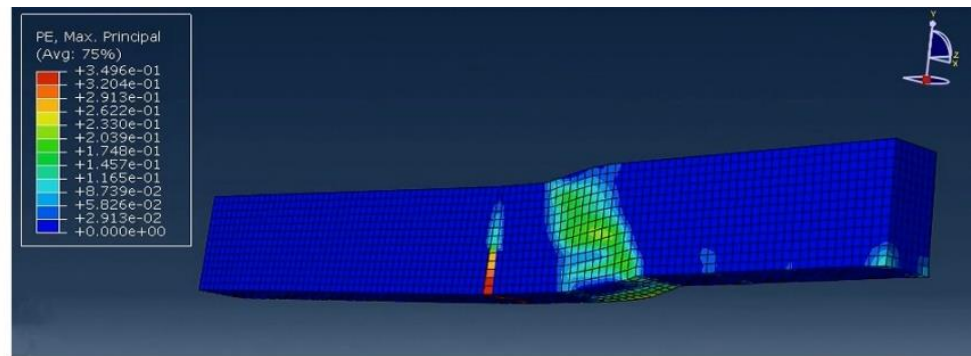

b)

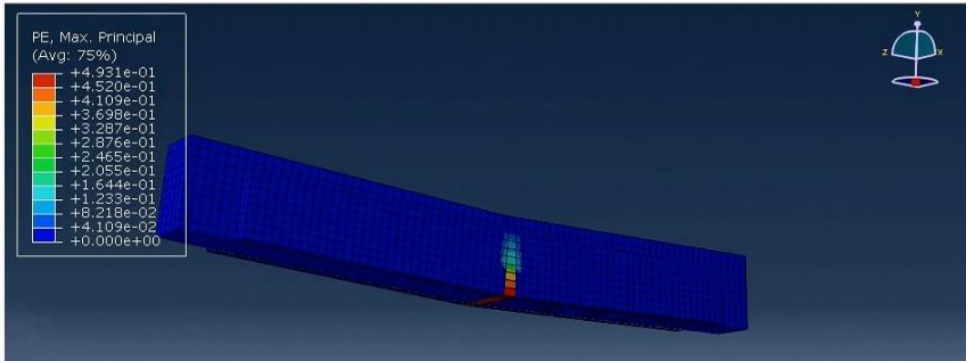

Figure 16. Failure mode of beams: (a) B type; (b) B-re type

\section{Discussion}

In this study, thickness of the prefabricated UHPFRC sheets were set to $3 \mathrm{~cm}$ to ensure the random distribution of steel fibers. Increasing thickness of the UHPFRC sheets is not logical but as an engineer's point of view, decreasing the thickness seems logical. By decreasing thickness of the UHPFRC sheets steel fibers shall not be randomly distributed. The authors believe that in case the thickness of the sheets be considered lower than the fiber's length, fibers will distribute in the longitudinal direction which may lead to increase in bearing capacity of the retrofitted beam. The effect of the thickness must be investigated in further studies.

\section{Conclusion}

This paper has discussed a retrofitting method for RC beams which have lack of shear reinforcement by using prefabricated UHPFRC sheets in order to increase bearing capacity and alter the sudden failure to a pre-warning failure. Experiments were conducted to investigate the efficiency of the method and FEM analysis have done to verify the laboratory results. The loading test have illustrated that this retrofitting method achieved significantly positive effects. Further important results are discussed below:

- Prefabricated UHPFRC sheets were able to increase the bearing capacity of RC beams by approx. $25 \%$ and alter the sudden failure mechanism to pre-warning failure mechanism.

- Using UHPFRC sheets caused significantly increase in beam's stiffness. According to results, steel fibers were able to absorb the loading energy and even increase the ductility of the RC beams up to $278 \%$. 
- Other advantages of using prefabricated UHPFRC sheets are as below:

- Protecting the RC beam from fire

- Protecting the RC beam from freeze and thaw cycles due to low water content of UHPFRC

- Easy to use and handle

- Low cost compare to other retrofitting methods and high durability

- In this study, adhesive epoxy used to bond the prefabricated UHPFRC sheets to beam's surface. Since there were no debonding between UHPFRC sheets and beam's surfaces, adhesive epoxy can be well used in strengthening methods and cost reduction.

\section{References}

[1] Wang, Jian, Hidenori Morikawa, and Tetsuo Kawaguchi. "Shear strengthening of RC beams using ultra-high-strength fibrereinforced concrete panels." Magazine of Concrete Research 67, no. 13 (2015): 718-729.

[2] Tayeh, Bassam A., BH Abu Bakar, MA Megat Johari, and Yen Lei Voo. "Mechanical and permeability properties of the interface between normal concrete substrate and ultra-high performance fiber concrete overlay." Construction and Building Materials 36 (2012): 538-548.

[3] Iskhakov, I., Y. Ribakov, K. Holschemacher, and T. Mueller. "High performance repairing of reinforced concrete structures." Materials \& Design 44 (2013): 216-222.

[4] Martinola, Giovanni, Alberto Meda, Giovanni A. Plizzari, and Zila Rinaldi. "Strengthening and repair of RC beams with fiber reinforced concrete." Cement and Concrete Composites 32, no. 9 (2010): 731-739.

[5] Rosignoli D, Simonelli F, Meda alberto, Rosignoli R, "High-Performance Fiber-Reinforced concrete jacketing in seismic retrofitting application." Concrete Repair Bulletin, September/October 2012.

[6] Bruhwiler E, "Rehabilitation and strengthening of concrete structures using Ultra-High Performance Fibre Reinforced Concrete." Concrete Repair, Rehabilitation and Retrofitting III, Taylor \& Francis Group, London, 2012.

[7] Sikadur 330® , “Construction Manual - Sikadur 330 2-part Epoxy Impregnation Resin”, Sika Gulf B.S.C C

[8] Obaidat, Yasmeen Taleb, Susanne Heyden, and Ola Dahlblom. "The effect of CFRP and CFRP/concrete interface models when modelling retrofitted RC beams with FEM." Composite Structures 92, no. 6 (2010): 1391-1398.

[9] SIMULIA ABAQUS, “ABAQUS Analysis 6.12 User's Manual”, ABAQUS Inc.

[10] Hsu, L. S., and C-TT Hsu. "Complete stress—strain behaviour of high-strength concrete under compression." Magazine of Concrete Research 46, no. 169 (1994): 301-312.

[11] Graybeal, Benjamin A. "Compressive behavior of ultra-high-performance fiber-reinforced concrete." ACI Materials Journal 104, no. 2 (2007): 146.

[12] Wille, K., S. El-Tawil, and A. E. Naaman. "Properties of strain hardening ultra high performance fiber reinforced concrete (UHP-FRC) under direct tensile loading." Cement and Concrete Composites 48 (2014): 53-66. 